\title{
Optimization and Characterization of Antimicrobial Agents Produced by Marine Aspergillus terreus SHE05 against Aeromonas hydrophila and other Applications
}

\author{
Hala H. Abd El-latif $(\mathbb{D}$, Sahar W.M. Hassan* (D) and Ehab A. Beltagy \\ Marine Microbiology Laboratory, Marine Environment Division, National Institute of Oceanography and \\ Fisheries, (NIOF), Alexandria, Egypt.
}

\begin{abstract}
Seven morphologically distinct marine fungi were isolated from sediment and Seawater samples at different sites along Alexandria seashore. Antagonism effect against Aeromonas hydrophila on purpose and other pathogen was estimated. The most promising isolate giving the highest antibacterial activity $(14 \mathrm{~mm})$ against $A$. hydrophila was morphologically and genetically identified as Aspergillus terreus SHE05 and the corresponding sequence was recorded in the GenBank database with accession no. MW772239. Time course production of the antibacterial agents by $A$. terreus SHE05 against $A$. hydrophila was studied showing the highest productivity after 5 days incubation. Multi-factorial design in terms of Placket Burman design was implemented to predict the critical factors influencing the production of the antibacterial agents by $A$. terreus SHE05 against $A$. hydrophila. The obtained results showed that malt extract, $\mathrm{pH}$ and temperature were the key factors affecting the antimicrobial activity. Consequently, Box-Behnken design was applied to estimate the optimized levels of each independent variable showing that the optimized conditions were malt extract, $3(\mathrm{~g} / \mathrm{l})$; peptone, $0.75(\mathrm{~g} / \mathrm{l})$; salinity, $50 \%$; $\mathrm{pH}, 4$; culture age, 4 days; inoculum size, $0.5 \mathrm{ml}$; temperature $30^{\circ} \mathrm{C}$ and incubation time 5 days, which caused an increase in the antimicrobial activity to $25 \mathrm{~mm}$, which denotes an approximately 1.8 fold increase comparing with the pre-optimized conditions. The potentiality of chloroform, hexane, petroleum ether and ethyl acetate for extraction of the active compounds was tested showing that ethyl acetate was the best. The extracted bioactive metabolites using ethyl acetate were tested as antimicrobial, anticancer, antiviral and antioxidant agents. Results showed reasonable activities. GCMS was used to recognize the active components in the ethyl acetate extract, showing that the major compound was the Dodecanamine, N,N-Dimethyl with RT 11.95, molecular weight 213, area \% (55.46) and molecular formula $\mathrm{C}_{14} \mathrm{H}_{31} \mathrm{~N}$.
\end{abstract}

Keywords: Fungi, optimization, response surface methodology, antimicrobial, anticancer, antiviral, antioxidant

*Correspondence: saharwefky@yahoo.com

(Received: April 03, 2021; accepted: July 29, 2021)

Citation: El Latif HHA, Hassan SWM, Beltagy EA. Optimization and Characterization of Antimicrobial Agents Produced by Marine Aspergillus terrus SHE05 against Aeromonas hydrophila and other Applications. J Pure Appl Microbiol. 2021;15(4):2367-2381. doi: 10.22207/JPAM.15.4.62

(C) The Author(s) 2021. Open Access. This article is distributed under the terms of the Creative Commons Attribution 4.0 International License which permits unrestricted use, sharing, distribution, and reproduction in any medium, provided you give appropriate credit to the original author(s) and the source, provide a link to the Creative Commons license, and indicate if changes were made. 


\section{INTRODUCTION}

The management of diseases caused by bacteria is increasingly difficult due to the capability of bacteria to make resistance to antibacterial compounds. ${ }^{1}$ Therefore, a critical need to achieve new groups of antagonistic agents exhibiting innovative mechanisms of action is essential. ${ }^{2}$ New developments in discovery of drugs from natural sources highlight on exploration of the marine environment to discover various novel and complex secondary metabolites for management of several diseases such as inflammatory condition, AIDS, cancer, malaria, fungal and viral diseases. ${ }^{3}$

Fungi produce a diversity of molecules with unique structures and display innumerable biological activities ${ }^{4-6}$ including anticancer, antiinflammatory, antiviral and antimicrobial. Since the past era, the number of antifungal and antibacterial metabolites from marine fungi have a rapid growing, making marine fungi a considered potential sources for natural metabolites. ${ }^{7}$

Aspergillus denotes a large various genus, comprise different filamentous fungal species of significant commercial and pharmaceutical values. ${ }^{8}$ Aspergillus is considered as the major source of fungal secondary metabolites and currently expanding its applications in different fields of pharmaceuticals and medicine. ${ }^{9-13}$
Secondary bioactive metabolites production by microorganisms is influenced by the species and strains in addition to their cultural and nutritional conditions. ${ }^{14}$ Minor alterations in medium conformation can significantly influence the quantitative and qualitative behavior of the secondary components together with the overall metabolic profiles of the microorganism. The optimization process considers to be convoluted due to the possible use of component that supports the growth as a substrate. ${ }^{15}$ Consequently, designing a suitable medium for cultivation is the most important for enhancing the yield of antimicrobial agents. ${ }^{16}$ Response surface methodology (RSM) is a statistical tool, which is a valuable to enhance the factors affecting the processes of fermentation and was used in different optimization studies. ${ }^{17-19}$

Although numerous studies have been directed to study the diversity of marine fungi, almost not enough information is accessible on their biotechnological activity. So, the purposefulness of the current research was assessment the potentiality of isolated marine fungus from the Mediterranean Sea as antimicrobial agents producer against the fish pathogen Aeromonas hydrophila. Afterwards, statistical optimization of culture condition targeting over-production and

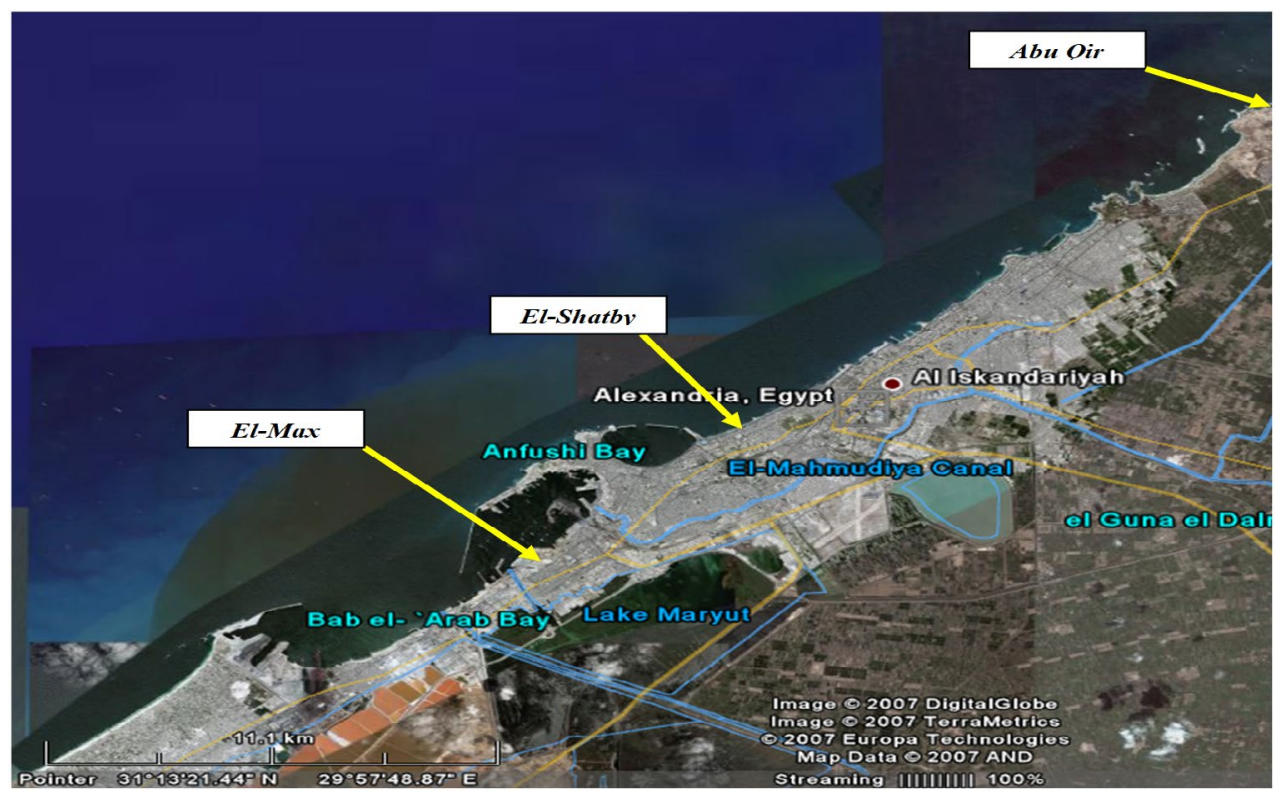

Fig. 1. Map of sampling area ${ }^{20}$. 
evaluation of different applications of the bioactive metabolites were inspected.

\section{MATERIALS AND METHODS \\ Samples collection}

Ten sediment samples were gathered from diverse sites along Alexandria seashore, Egypt, including Abu-Qir, El- Mex and El -Shatby (Fig. 1) at water depth ranging from 0.5 to 1 $\mathrm{m}$. The collected samples were retained in the polyethylene bags, kept in freezing box at $4-8^{\circ} \mathrm{C}$ and conveyed to the lab for microbial analysis. Isolation and purification of marine fungi

Sediments were air dried for 2 days before fungal isolation. Subsequent dilution of sediment samples was carried out $(1: 10)$ using sterilized seawater. $1 \mathrm{ml}$ of each sample was spread onto the prepared potato dextrose agar medium. ${ }^{21}$ Regarding the collected water samples, $1 \mathrm{ml}$ of each sample was used to inoculate the isolation medium. Isolation medium was prepared with seawater and chloramphenicol $(250 \mathrm{mg} / \mathrm{L}$ ) was added as antiseptic agent. The inoculated plates were incubated at $30^{\circ} \mathrm{C}$ for one week. The plates were regularly observed. Dissimilar colonies were then removed to new plates for subsequent purification. Each purified colony was selected and subculture was carried out on the prepared slants using the same isolation media and kept for more studies. ${ }^{22}$ The isolates were kept in glycerol stock $(40 \%)$ seawater medium at $-80^{\circ} \mathrm{C}$.

\section{Target pathogenic microorganisms}

The reference pathogenic bacteria including Gram positive bacteria (Bacillus subtilis ATCC 6633 and Staphylococcus aureus ATCC 25923), Gram-negative bacteria (Escherichia coli ATCC 19404, Enterococcus faecalis ATCC 29212, Klebsiella pneumoniae ATCC 13883, Pseudomonas aeruginosa ATCC 15442 and Aeromonas hydrophila) were kindly provided by Microbiology Lab, Marine invironmental Division, NIOF, Alexandria, Egypt. The obtained pathogens were preserved at $-20^{\circ} \mathrm{C}$ using glycerol $(15 \%, v / v)$ for consequent using.

\section{Screening for fungal antagonistic effect}

The antimicrobial activity of the isolated marine fungi was assessed against the previously mentioned target pathogenic microorganisms using well cut diffusion technique. ${ }^{23}$

\section{Molecular identification of fungal candidate}

The fungal isolate was grown in sterile Petri plates containing autoclaved potato dextrose agar (PDA) medium and incubated for 7 days at $28^{\circ} \mathrm{C}$. The culture was sent to the Molecular Biology Research Unit, Assiut University for molecular identification. First, PCR was performed using ITS4 (reverse) and ITS1 (forward) primers with the following composition: ITS4 (5'- TCC TCC GCT TAT TGA TAT GC - 3 ' and ITS1 (5' - TCC GTA GGT GAA CCT GCG G - 3'). The same two primers were used for sequencing of the purified PCR product $^{24}$. Analysis of the gained sequences were done by (BLAST) program from the National Center of Biotechnology Information (NCBI) website. Phylogenetic analysis was done using MegAlign (DNA Star) software version 5.05.

Optimization of fermentation conditions for antimicrobial agents production

\section{Effect of incubation period}

Antimicrobial activity of fungal filtrate was monitored at different time intervals during 7 days using well cut diffusion technique. ${ }^{23}$

\section{The Plackett-Burman design}

The Plackett-Burman experimental design ${ }^{25,26}$ was applied to establish the significance of different cultural and environmental factors for higher production of antimicrobial agents in liquid cultures. Screening of seven independent variables was carried out. For every variable, low (-) and high (+) levels were examined. Eight trials were designed in triplicate and the average of inhibition zone diameters was taken as the responses (Table 3).

$$
E_{x i}=\left(\Sigma M_{i}+-\Sigma M_{i}-\right) / N
$$

Where $E_{x i}$ is the variable main effect, $M_{i}-$ and $M_{i+}$ are the inhibition zone diameter $(\mathrm{mm})$ at the low and high levels, respectively; $\mathrm{N}$ represents the number of experiments. p-values and Statistical t-values were considered for significance determination using Microsoft Excel 2010.

\section{Box-Behnken design}

The Box-Behnken design was applied after assessing the significance of independent factors ${ }^{27}$ for further estimation of the optimal levels with regard to production of the antimicrobial compounds. The optimization practice involved 
performance of the statistically designed experiments to determine the coefficients, detecting the response and testing the mode adequacy. The low, basal and high levels of every factor were recorded as $(-1),(0)$ and $(+1)$, respectively (Table 4$)$. The proposed matrix contained 15 combinations designed in duplicate and mean results of bioactive compounds production were recorded. To expect the optimal values, fitting of the second order polynomial function was done to determine the association between the response and independent variables as follows:

$Y=\beta_{0}+\beta_{1} X_{1}+\beta_{2} X_{2}+\beta_{3} X_{3}+\beta_{12} X_{1} X_{2}+$ $\beta_{13} x_{1} x_{3}+\beta_{23} x_{2} x_{3}+\beta_{11} x_{1}^{2}+\beta_{22} x_{2}^{2}+\beta_{33} x_{3}^{2}{ }^{2} x_{1}$

Where $Y$ is the predicted response, $\beta_{0}$ is the Regression coefficient, $\mathrm{X}_{3}, \mathrm{X}_{2}$ and $\mathrm{X}_{1}$, are the independent variables, $\beta_{1}, \beta_{2}$, and $\beta_{3}$ are linear coefficients, $\beta_{23}, \beta_{13}$, and $\beta_{12}$ are second order interaction coefficients, and the $\beta_{33}, \beta_{22}$, and $\beta_{11}$ are quadratic coefficients. Analysis of the experimental data was carried out using Statistica 10.0.27,28 Other applications of the active metabolites Antimicrobial activity against other pathogenic microorganisms

Antimicrobial action of crude extract was tested against other reference pathogenic bacteria including E. coli ATCC 8739 and S. aureus ATCC 6538 in addition to instead of the highlighted part pathogenic fungi including $A$. niger and $C$. albicans ATCC 10221 using agar well diffusion technique as was previously described.

\section{Antitumor activity}

The bioactive compounds produced by $A$. terreus SHE05 were examined for their cytotoxic activity toward three tumor cell lines, coded MCF-7 (Breast cancer cell-line), HepG2 (liver hepatocellular carcinoma) and HCT 116 (human colon carcinoma) according to a previous method. ${ }^{29}$ The cell viability percentage was calculated as follow:

$\%$ Cell viability $=$ Mean Abs (control) Mean Abs (test) $X 100$

\section{Antiviral activity}

HEp-2 cells monolayers were used to test the cytotoxicity of the extracted bioactive compounds..$^{30}$ The antiviral activity was detected as follows:

Absorbance of the compound - Absorbance of the viral control

Absorbance of the cell control - Absorbance of the viral control

\section{Antioxidant activity}

Antioxidant activity was tested using the DPPH (2,2-diphenyl-1-picryl-hydrazyl-hydrate) stable free radical scavenging assay as was previously described. ${ }^{29}$

\section{Extraction of the bioactive metabolites}

Extraction procedure was owing to the method of Calado et al. ${ }^{21}$ Briefly, Different solvents representing different polarities including hexane, chloroform, ethyl acetate and petroleum ether were used for extraction of the desired bioactive metabolites aiming to find one of the tested solvents match that of the desired compounds, making the dissolving and separation more easily. Gas chromatography / Mass spectrometry (GC) MS) analysis

The chemical composition of the extract was determined using GC- MS (Hewlett Packard, HB 5890 gas-liquid chromatography (GLC) paired with 5989 B series mass spectrometer (MS). Reading analysis of mass spectra data were created by a computerized library-searching program (Database/Wiley 275.1) and by considering the fragmentation pattern of released compound resulting from mass spectrometry evaluation. Each compound was qualitatively calculated following this formula: Compound Concentration $\%=P 1 / P 2$ $* 100$ where: $\mathrm{P} 1=$ the peak area of the compound, and $\mathrm{P} 2=$ whole peak areas in the fractionated extract. Descriptions of the peaks were done using Wiley mass spectral data base library. ${ }^{25}$

\section{RESULTS AND DISCUSSION}

Isolation of marine fungi and screening for antibacterial potentiality

Seven morphologically distinct fungal isolates namely (F1-F7) were isolated from the collected water and sediment samples coded (S1S10) from Abu Qir, Alexandria, Egypt and screened for production of antibacterial agents against different pathogenic bacterial indicators using well cut diffusion technique. Results in Table 1 indicated 
variation in the antagonistic effect against the used pathogenic strains. The highest antibacterial activity was against $A$. hydrophila with inhibition zone diameter ( $14 \mathrm{~mm}$ ) followed by $B$. subtilis ATCC 6633 and E.coli ATCC 19404 recording inhibition zone diameters of $13 \mathrm{~mm}$ and $12 \mathrm{~mm}$, respectively.

Accordingly, the fungal isolate F3 was selected to complete the current investigation as it exhibited broad spectrum of antibacterial activity against the tested pathogenic bacteria and $A$. hydrophila was selected as the most susceptible bacterial pathogen to the bioactive metabolites produced by F3. In contrast, isolates F2, F4 and F5 did not exhibit any antibacterial activity.

This variation is based on the capability of fungus to produce inhibitory metabolites and the type of pathogenic bacterial structure and susceptibility of Gram positive and Gram- negative bacteria to the bioactive metabolites due to cell wall structure. ${ }^{31}$ The antagonistic activity of the fungal isolates in the current study was more noticeable toward Gram negative bacteria, which is a promising for control of the more resistant Gram negative bacteria. In a parallel study, twenty fungal isolates were tested for antibacterial activity regarding human pathogens. Isolate MF-1 showed promising activity against Bacillus subtilis $(19 \mathrm{~mm})$; Streptococcus pyrogenes $(10 \mathrm{~mm}) ;$ S.aureus (17 $\mathrm{mm}) ;$ Sphingomonas pacucimobilis (16 $\mathrm{mm}) ; B$. coagulans $(17 \mathrm{~mm})$; Corynibacterium glutamicum $(25 \mathrm{~mm})$; Klebsiella pneumonia $(20 \mathrm{~mm})$ and
E. coli $(15 \mathrm{~mm}){ }^{32}$ A recent study examined the antimicrobial activity of six fungal isolates against 9 bacterial pathogens and the results concluded that more susceptibility to the active compounds was observed for Gram-positive bacteria. ${ }^{33}$

Identification of the potent fungal isolate (F3)

F3 was exposed to molecular characterization and had a multiple alignment with the highest homology using blast search computer based program on NCBI platform. The identified sequence was deposited in NCBI as Aspergillus terreus SHE05 with accession no. MW772239, where Fig. 2 representing the phylogenetic tree according to sequences of 185 rDNA region (ITS). Fig. 3 A showed the morphology of $A$. Aspergillus terreus SHE05 on potato dextrose agar medium, the electron microscopic examination of $A$. Aspergillus terreus SHE05 was shown in Fig. $3 \mathrm{~B}$, $C, D$ and $E$ using different magnifications.

Optimization of antibacterial agent(s) production Influence of incubation period on antibacterial potential of $A$. terreus SHE05

Proper determination of specific incubation requirement is of great significance for maximum gathering of the metabolite. ${ }^{34}$ As revealed in Table 2, the antibacterial activity against $A$. hydrophila improved with increasing the incubation period reaching the highest antibacterial activity after five days with inhibition zone diameter of $14 \mathrm{~mm}$ followed by decrease in the activity reaching $10 \mathrm{~mm}$ after 6 days, and

Table 1. Antibacterial potential of the isolated marine fungi against different reference pathogenic indicators

\begin{tabular}{|c|c|c|c|c|c|c|c|}
\hline \multirow[b]{2}{*}{$\begin{array}{l}\text { Isolate } \\
\text { Code }\end{array}$} & \multirow[b]{2}{*}{ A. hydrophila } & \multicolumn{5}{|c|}{ Antibacterial activity (expressed as inhibition zone diameter $(\mathrm{mm}$ ) against } & \multirow{2}{*}{$\begin{array}{l}\text { K. pneumoniae } \\
\text { ATCC } 13883\end{array}$} \\
\hline & & $\begin{array}{c}\text { S. aureus } \\
\text { ATCC } 25923\end{array}$ & $\begin{array}{c}\text { E.coli } \\
\text { ATCC } 19404\end{array}$ & $\begin{array}{c}\text { P.aeruginosa } \\
\text { ATCC } 15442\end{array}$ & $\begin{array}{l}\text { B. subtilis } \\
\text { ATCC } 6633\end{array}$ & $\begin{array}{c}\text { E. faecalis } \\
\text { ATCC } 29212\end{array}$ & \\
\hline F1 & 11 & 0 & 0 & 0 & 11 & 0 & 0 \\
\hline F 2 & 0 & 0 & 0 & 0 & 0 & 0 & 0 \\
\hline F 3 & 14 & 0 & 12 & 12 & 13 & 0 & 0 \\
\hline F 4 & 0 & 0 & 0 & 0 & 0 & 0 & 0 \\
\hline F 5 & 0 & 0 & 0 & 0 & 0 & 0 & 0 \\
\hline F 6 & 23 & 0 & 0 & 0 & 0 & 0 & 0 \\
\hline F 7 & 0 & 12 & 13 & 0 & 0 & 0 & 0 \\
\hline
\end{tabular}

Table 2. Influence of incubation period on antibacterial activity against $A$. hydrophila

\begin{tabular}{lccccc}
\hline Incubation time (day) & 3 & 4 & 5 & 6 & 7 \\
\hline $\begin{array}{l}\text { Diameter of inhibition } \\
\text { zone (mm) }\end{array}$ & 12 & 13 & 14 & 10 & 0 \\
\end{tabular}

no antibacterial activity was observed at 7th day. In line with the current study, it was reported that the maximum antibacterial activity of Aspergillus terreus was on $5^{\text {th }}$ day of incubation and remained less or more stable until $9^{\text {th }}$ day and then declined ${ }^{35}$. It was mentioned that the 


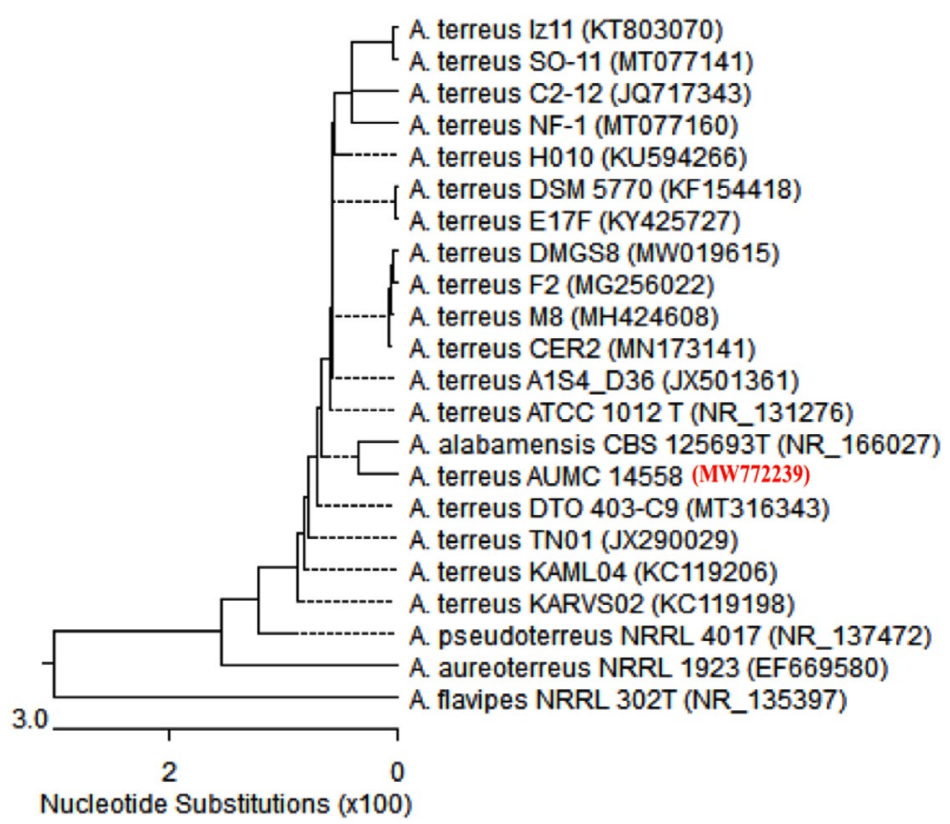

Fig. 2. Phylogenetic tree depending on ITS region sequence of $18 \mathrm{~S}$ rDNA of the fungal isolate in the current investigation (Aspergillus terreus SHE05).

(A)

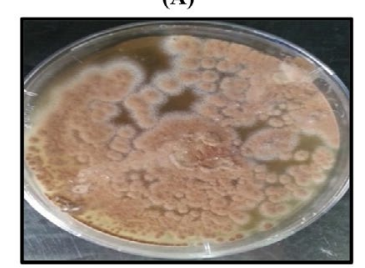

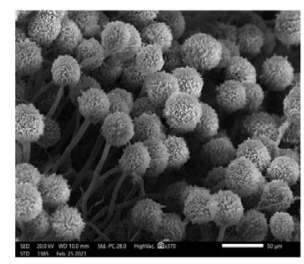

(B)

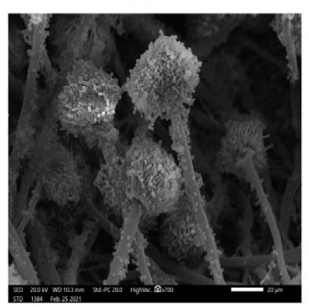

(D)

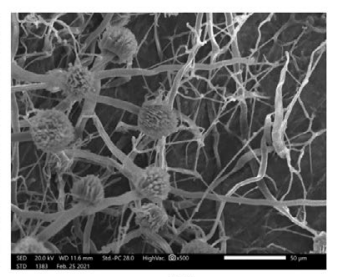

(C)

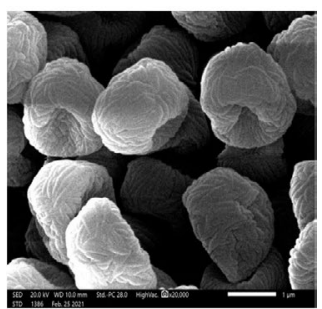

(E)
Fig. 3. Colony morphology of Aspergillus terreus SHEO5 on potato dextrose agar medium (A) and electron microscopic photographs of Aspergillus terreus SHE05 using magnification of $370 \times(B), 500 \times(C), 700 \times(D)$, 20000x (E). time for bioactive compounds production varies according to the cultivation conditions and the strain. ${ }^{35}$ More or less incubation period could be detected in other studies. ${ }^{36,37,38}$

\section{Optimization of fermentation conditions}

Selection of the significant factors by applying Plackett- Burman experimental design

The Plackett-Burman experimental design was adopted to determine the qualified significance of different parameters affecting the antimicrobial agents production by $A$. terreus SHEO5 in liquid cultures using 7 independent variables in a high (+) and low (-) levels setted in 8 trials as was previously described and shown in Table 3.

The main effect of each factor on the antagonistic action of $A$. terreus SHE05 against A. hydrophila was estimated and revealed in Table 3 and presented in Fig. 4. Results revealed that the increase of peptone and malt extract concentrations had positive main effects on antibacterial activity, while the other parameters had negative main effects. The most significant variables (malt extract, $\mathrm{pH}$ and temperature) were predicted using t-test $(P<0.05)$. Owing to Plackett-Burman design results, the subsequent fermentation settings were predictable to be close 
to optimal levels: malt extract, 2.25 ; peptone, 0.75 (g/l); salinity, 50\%; $\mathrm{pH}, 5$; culture age, 4 days, inoculum size, $0.5 \mathrm{ml}$; temperature, 25 and incubation time 5 days. In a comparable study, the optimum conditions for the antagonistic activity of Aspergillus flavipes strain HN4-13 against aquatic Vibrio. Cholera, V. anguillarum, V. parahemolyticus and $V$. harveyi were $0.25 \%$ glucose, $0.3 \%$ peptone, $0.1 \% \mathrm{NaH} 2 \mathrm{PO} 4,3 \% \mathrm{NaCl}, 3 \% \mathrm{KCl}, 4.5 \%$ inoculum size, $\mathrm{pH} 7.0,160 \mathrm{rpm} / \mathrm{min}$ and $32^{\circ} \mathrm{C}$ for eight days. Such conditions of this study exhibited a $62.3 \%$ increase in the activity. ${ }^{39}$

\section{Recognizing the optimal production conditions using Box-Behnken design}

Box-Behnken design was used to define the optimal value of each independent parameter including malt extract $\left(X_{1}\right), \mathrm{pH}\left(X_{2}\right)$ and incubation temperature $\left(X_{3}\right)$. As represented in Table 4, the design embraced 15 trials, each variable was studied at 3 dissimilar levels (1,0 and -1), and the detected antibacterial activities $(\mathrm{mm})$ were recorded. According to the value of $\mathrm{R} 2$ (0.8), the experimental records were relatively fitting. In this study, results of optimization were

Table 3. Levels of independent factors and results of Plackett-Burman experimental design

\begin{tabular}{|c|c|c|c|c|c|c|c|c|}
\hline Trials & $\mathrm{ME}(\mathrm{g} / \mathrm{l})$ & $P(g / I)$ & $\mathrm{pH}$ & S (\%) & CA (day) & IS (ml) & $\mathrm{T}(\mathrm{oC})$ & $\mathrm{IZ}(\mathrm{mm})$ \\
\hline 1 & $-1[0.75]$ & $-1[0.25]$ & $-1[5]$ & $1[150]$ & $1[6]$ & $-1[0.5]$ & $-1[25]$ & 22 \\
\hline 2 & $1[2.25]$ & $-1[0.25]$ & $-1[5]$ & $-1[50]$ & $1[6]$ & $1[1.5]$ & $1[35]$ & 25 \\
\hline 3 & $-1[0.75]$ & $1[0.75]$ & $-1[5]$ & $-1[50]$ & $-1[4]$ & $1[1.5]$ & $1[35]$ & 19 \\
\hline 4 & $1[2.25]$ & $1[0.75]$ & $-1[5]$ & $1[150]$ & $-1[4]$ & $-1[0.5]$ & $-1[25]$ & 31 \\
\hline 5 & $-1[0.75]$ & $-1[0.25]$ & $1[7]$ & $1[150]$ & $-1[4]$ & $1[1.5]$ & $1[35]$ & 15 \\
\hline 6 & $1[2.25]$ & $-1[0.25]$ & $1[7]$ & $-1[50]$ & $-1[4]$ & $-1[0.5]$ & $-1[25]$ & 24 \\
\hline 7 & $-1[0.75]$ & $1[0.75]$ & $1[7]$ & $-1[50]$ & $1[6]$ & $-1[0.5]$ & $-1[25]$ & 21 \\
\hline 8 & $1[2.25]$ & $1[0.75]$ & $1[7]$ & $1[150]$ & $1[6]$ & $1[1.5]$ & $1[35]$ & 18 \\
\hline 9 & $0[1.5]$ & $0[0.5]$ & $0[6]$ & $0[100]$ & $0[5]$ & $0[1]$ & $0[30]$ & 18 \\
\hline $\begin{array}{l}\text { Main } \\
\text { effect }\end{array}$ & 5.25 & 0.75 & -4.75 & -0.75 & -0.75 & -0.75 & -5.25 & \\
\hline
\end{tabular}

ME: malt extract, P: peptone, S: salinity, CA: culture age, IS: inoculum size, T: temperature, IZ: inhibition zone.

-1 and +1 represent the coded levels (low and high) of the independent variable. Values of inhibition zone diameters are the average of duplicate cultivation experiments $\pm \mathrm{SD}$.

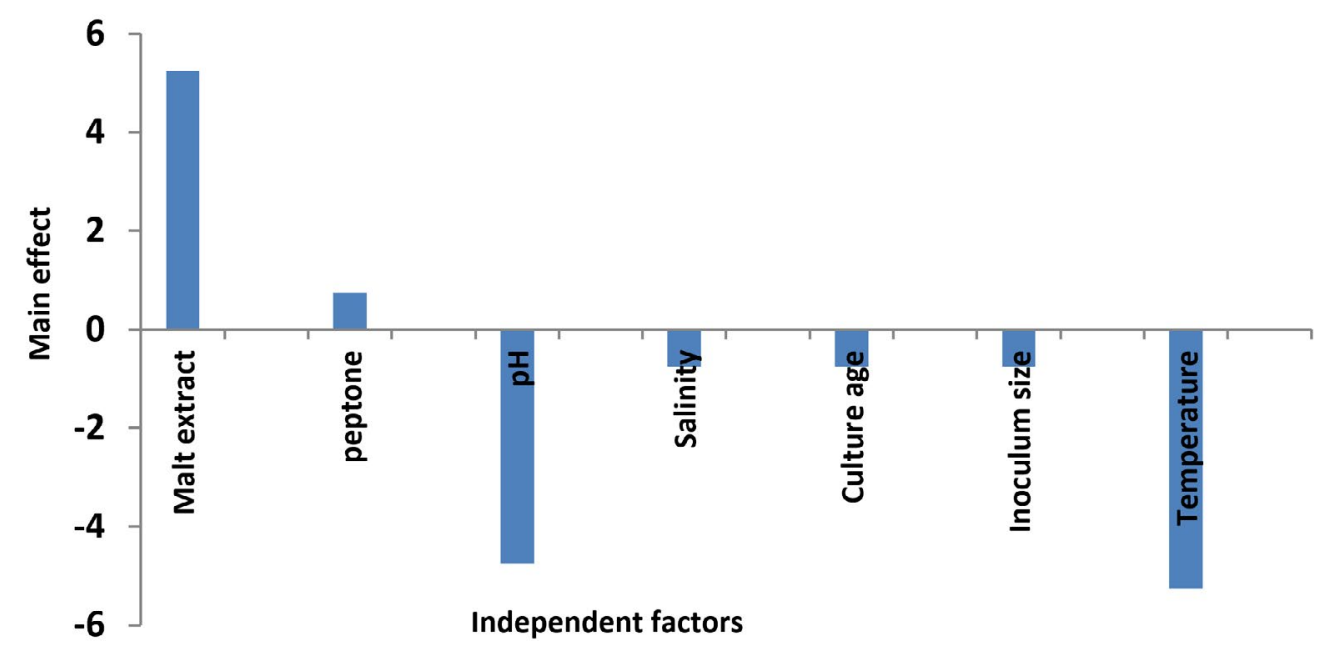

Fig. 4. Main effect of independent factors affecting antimicrobial agents production by Aspergillus terreus SHE05. 


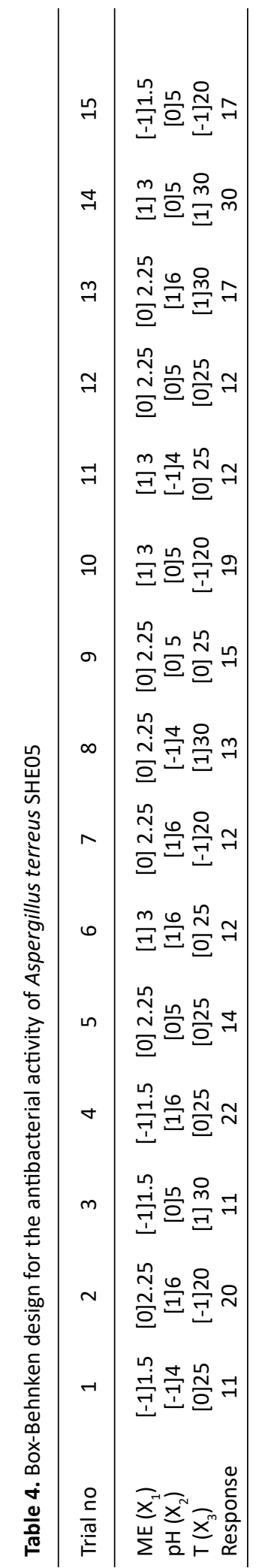

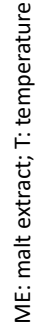

examined both graphically and mathematically. The mathematical solution was obtained using Statistica software. Verifying the accuracy of model prediction revealed that the observed and predicted antibacterial activities (IZ) were closely correlated to each other (Fig. 5).

$$
\begin{array}{r}
Y=13.67+3.75 X_{1}-0.12 X_{2}-0.87 X_{3}-4.74 \\
X_{1} X_{2}+7.97 X_{1} X_{3}+3.00 X_{2} X_{3}+1.91 X^{2}{ }_{1}+0.66 X^{2}{ }_{2}+1.17 \\
X^{2}{ }_{3}
\end{array}
$$

As, $Y$ is the response, the antibacterial activity (AU) and $X_{3}, X_{2}$ and $X_{2}$ are the coded levels of the independent parameter; Malt extract, $\mathrm{pH}$ and incubation temperature, respectively. Overall results suggested that the predicted optimized conditions were: malt extract, $3(\mathrm{~g} / \mathrm{l})$; peptone, $0.75(\mathrm{~g} / \mathrm{l})$; salinity, $50 \%$; $\mathrm{pH}, 4$; culture age, 4; inoculum size, $0.5 \mathrm{ml}$; temperature, $30^{\circ} \mathrm{C}$ and incubation time 5 days

Verifying the accuracy of model displayed an increase in the antibacterial activity to $25 \mathrm{~mm}$ representing 1.8 fold increase with comparing to the basal settings before applying the Box design as shown in Table 5. The overall results confirmed the accuracy of the assumed optimization approach in addition to less time consuming.

Our results achieved higher percentage (89.29\%) of antibacterial activity against A. hydrophila compared to a previous study ${ }^{39}$ who reached to $62.3 \%$ rise in the activity of the active metabolites produced by Aspergillus flavipes against Vibrio harveyi by employing Plackett-Burman and Box-Behnken designs and the optimum settings were as follow: $3 \%$ glucose, $0.3 \%$ peptone, $3 \% \mathrm{NaCl}, 0.1 \% \mathrm{NaH}_{2} \mathrm{PO}_{4}, 0.25 \% \mathrm{KCl}$, $5 \%$ inoculum size, $\mathrm{pH} 7.0,160 \mathrm{rpm} / \mathrm{min}, 32^{\circ} \mathrm{C}$, for eight days. In accordance with our results 1.9 fold increase of antimicrobial agents production was predicted in a comparable study. ${ }^{30}$

Table 5. Verification experiment showing antimicrobial activity of $A$. terreus SHEO5 against $A$. hydrophila grown under the optimized conditions in comparison with the basal conditions

Inhibition zone diameter ( $\mathrm{mm}$ )

$\begin{array}{ll}\text { Optimized conditions } & 25 \mathrm{~mm} \\ \text { Basal conditions } & 14 \mathrm{~mm}\end{array}$


The effect of pairwise factors and their interactions were studied and the corresponding Response surface plots were presented in Fig. 6. Overall results concerning the antagonistic effect of the produced bioactive compounds from $A$. Aspergillus terreus SHEO5 against aquatic pathogen $A$. hydrophila in vitro would provide the promising prospect in vivo aquatic application.

\section{Extraction of the bioactive compounds}

Extraction is the decisive first stage and necessary to extract the desired components for subsequent separation and characterization. Different solvents exhibiting diverse polarities like hexane, chloroform, ethyl acetate and petroleum ether were used to extract the antimicrobial compounds.

It was observed that extract of ethyl acetate was the most active against $A$. hydrophila and exhibited the maximum diameter of inhibition zone $(25 \mathrm{~mm})$, followed by chloroform and hexane with $20 \mathrm{~mm}$, while the lowest inhibition zone diameter $(16 \mathrm{~mm})$ was recorded upon using petroleum ether (Table 6). In accordance, ethyl acetate had the highest effeciency for taking out the desired bioactive metabolites. ${ }^{30,40}$ It was stated that the antagonistic activity of the metabolites produced are diverse dependent on the used solvent and the nature of the pathogenic indicators tested. ${ }^{41,42}$

Table 6. Effect of different solvent extracts on $A$. hydrophila growth

\begin{tabular}{lcccc}
\hline Solvent & Chloroform & $\begin{array}{c}\text { Ethyl } \\
\text { acetate }\end{array}$ & $\begin{array}{c}\text { Petroleum } \\
\text { ether }\end{array}$ & Hexane \\
\hline $\mathrm{IZ}(\mathrm{mm})$ & 20 & 25 & 16 & 20 \\
\hline
\end{tabular}

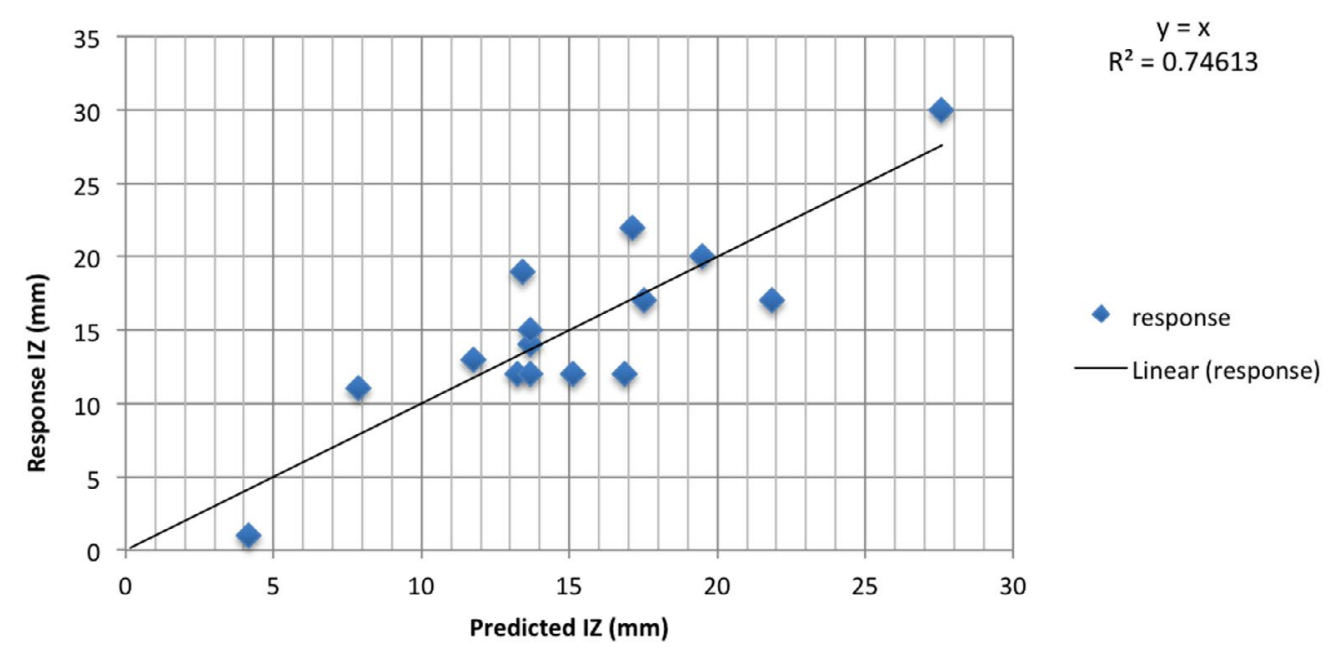

Fig. 5. Residual diagnostics of quadratic model surface: The predicted response versus observed antimicrobial activity of Aspergillus terreus SHE05.
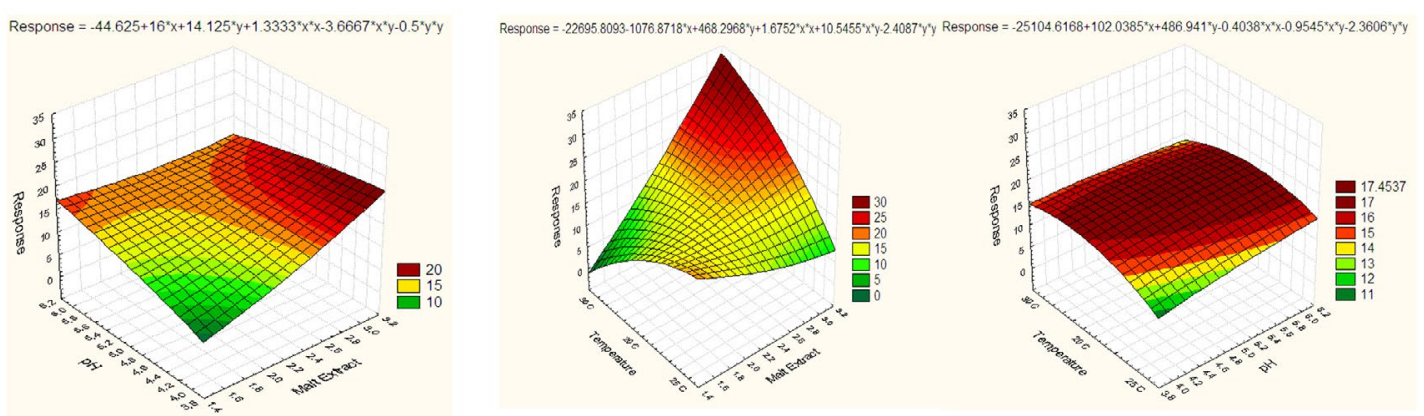

Fig. 6. Response surface plots displaying effect and interaction of variables on diameter of inhibition zones constructed on the results of Box-Behnken design. 
Other applications of the extracted active metabolites

\section{Antimicrobial activity}

The antimicrobial activity was further tested against other reference pathogenic bacteria and fungi. Results shown in Table 7 revealed that the maximum antibacterial activity was recorded against $E$. coli ATCC 8739 with inhibition zone diameter $(17 \mathrm{~mm})$, followed by $S$. aureus (ATCC 6538) recording $15 \mathrm{~mm}$. Reasonable antifungal activity was also observed against $C$. albicans ATCC 10221 and $A$. niger recording inhibition zone diameter as $21 \mathrm{~mm}$ and $15 \mathrm{~mm}$. The ethyl acetate crude extract was the favorable solvent exhibiting the highest bioactivity against Staphylococcus aureus (MTCC96), Micrococcus luteus (MTCC106), Pseudomonas aeruginosa (MTCC326), Enterococcus faecalis (MTCC439) and Proteus mirabilis (MTCC1429) as was previously reported. ${ }^{43,44}$ Bioactivity of marine Penicillium. citrinum strain $\mathrm{Cas} 03$ and Aspergillus. unguis strain CasO2 isolated from sponge Callyspongia $s p$. displayed prospective antimicrobial activities against E.coli and S. aureus. ${ }^{40}$

\section{Anticancer activity}

A main challenge is the fruitful treatment of cancer due to occurrence of drug inactivation by cancer cells. ${ }^{45}$ In the current investigation, the ethyl acetate crude extract showed reliable anticancer effect against three different cell lines: Breast cancer cell line (Mcf 7), Human colonic carcinoma cell line (HCT 116) and human liver cancer cell line (HepG2) showing moderate effect (71.6\%) against HCT 116 with IC50 of 1163816.76 and HepG2 (68\%) with IC50 4104.842 using the concentration $5000 \mu \mathrm{g} / \mathrm{ml}$ as presented in Fig. 7. Low anticancer activity was detected against Mcf 7 (37\%) with IC50 of $6491.51 \mu \mathrm{g} / \mathrm{ml}$. Moreover, effect of the active metabolites on the cell morphology was also detected as shown in Fig. 8. Austocystin D derived from Aspregillus recommended to have anticancer potential. Also, Asp.t derived (TC-A) Terrecyclic acid A displayed cytotoxicity toward human breast cancer MCF-7, human CNS cancer SF-268 and human lung cancer $\mathrm{NCl}-\mathrm{H} 460 .{ }^{42}$ The anticancer activity of Aspergillus metabolites was proven in in a previous study. ${ }^{46}$

\section{Antiviral activity}

Active metabolites in the ethyl acetate extract were tested as antiviral agents against Hepatitis A virus (HAV), HSV1 and CoxB4 showing a concentration dependent manner (Table 8) and the highest antiviral activity (87.82\%) was detected against HAV at $1250 \mu \mathrm{g} / \mathrm{ml}$ without cytotoxicity on vero cells followed by CoxB4 with inhibition of $84.63 \%$, while very low antiviral activity was detected against HSV1 (9.64\%) using the same tested concentration $(1250 \mu \mathrm{g} / \mathrm{ml})$ of the active metabolites. In a previous study, Aspergillipeptide D gained from Aspergillus sp. SCSIO 41501 has shown antiviral action against HSV-1. ${ }^{35}$

Table 7. Antimicrobial activity against other pathogenic microorganisms

\begin{tabular}{lcccc}
\hline $\begin{array}{l}\text { Pathogenic } \\
\text { microorganisms }\end{array}$ & $\begin{array}{c}\text { E.coli } \\
\text { ATCC 8739 }\end{array}$ & $\begin{array}{c}\text { S. aureus } \\
\text { ATCC 6538 }\end{array}$ & $\begin{array}{c}\text { C. albicans } \\
\text { ATCC 10221 }\end{array}$ & A. niger \\
\hline $\begin{array}{l}\text { Inhibition zone } \\
\text { diameter (mm) }\end{array}$ & 17 & 15 & 21 & 15 \\
\hline
\end{tabular}
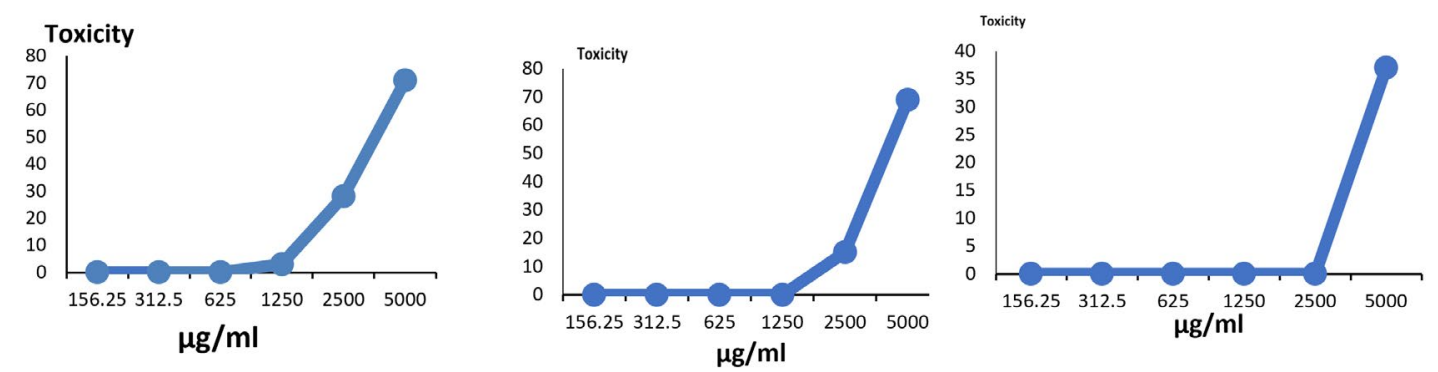

Fig. 7. Effect of different concentrations of ethyl acetate crude extract on HepG2 (A); HCT116 (B) and Mcf7 cell lines (C). 


\section{Antioxidant activity}

Antioxidant activity of ethyl acetate extract was tested using different concentrations (0.5-2 $\mathrm{mg} / \mathrm{ml})$, using 2,2-diphenyl-1-picryl-hydrazylhydrate (DPPH) free radical scavenging technique. Results (Fig. 9) revealed that the maximum DPPH activity was $83.68 \%$ with an IC50 of $50.65 \mu \mathrm{g} / \mathrm{ml}$.
In harmony with our results, investigating the antioxidant potential of different fungal crude extracts isolated from Eugenia jambolana was studied showing that Chaetomium sp. and Aspergillus sp. had the maximum antioxidant activity (80\%), followed by Aspergillus niger and $A$. peyronelii, which had $72 \%$ and $71 \%$ of
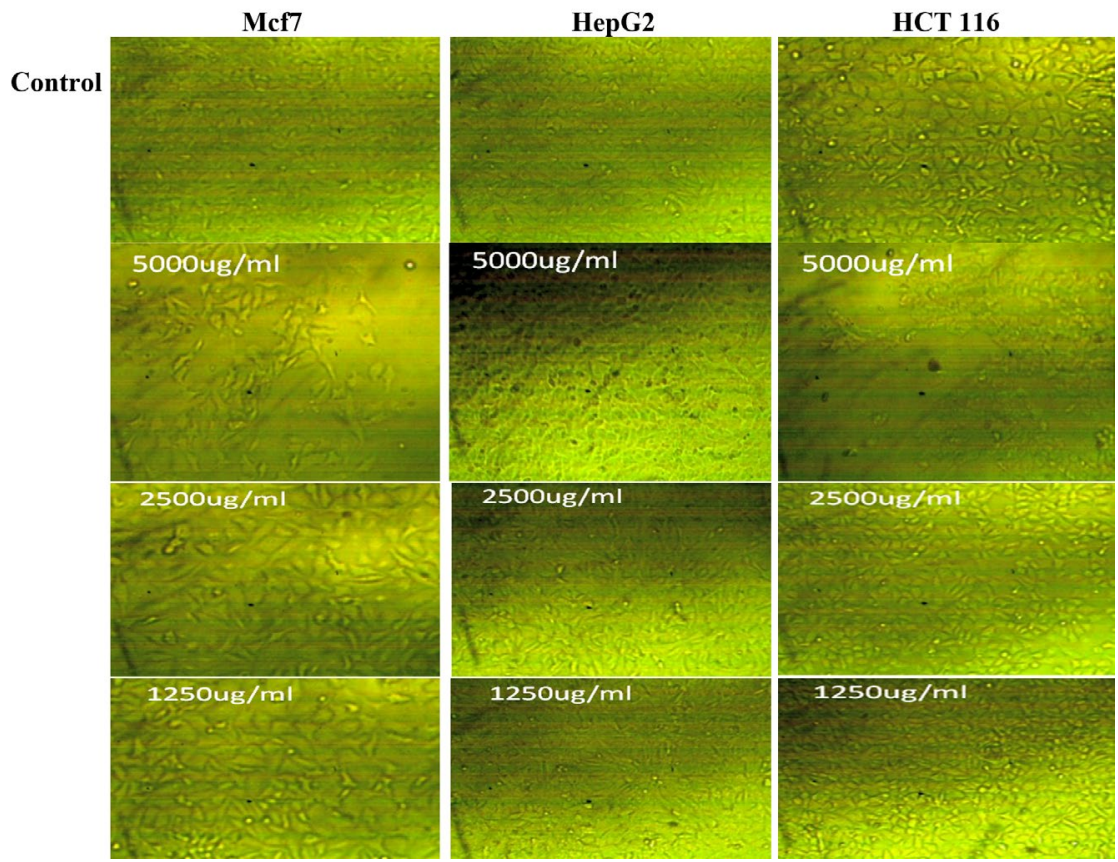

Fig. 8. Anticancer potentiality of active metabolites produced by Aspergillus terreus SHE05 against (A): Mcf7, HepG2 and HCT 116 using 1250, 2500 and $5000 \mu \mathrm{l} / \mathrm{ml}$ of the extract.

Table 8. Antiviral activity of metabolites in the ethyl acetate extract

\begin{tabular}{|c|c|c|c|c|c|c|c|c|c|c|}
\hline Test & $\begin{array}{c}\mu \mathrm{g} / \mathrm{ml} \\
\mathrm{CA}\end{array}$ & & O.D. & & $\begin{array}{l}\text { Mean } \\
\text { O.D }\end{array}$ & SDE & viability & toxicity & $\begin{array}{c}\text { Viral } \\
\text { activity \% }\end{array}$ & $\begin{array}{l}\text { Antivira } \\
\text { effect \% }\end{array}$ \\
\hline Control & & 0.305 & 0.326 & 0.323 & 0.318 & 0.005679 & 100 & 0 & & \\
\hline vero & & 0.105 & 0.113 & 0.124 & 0.114 & 0.004 & 35.84 & 64.154 & 100 & 0 \\
\hline \multirow[t]{4}{*}{ HSV1 } & 1250 & 0.14 & 0.129 & 0.132 & 0.133 & 0.002 & 42.03 & 57.96 & 90.35 & 9.64 \\
\hline & 625 & 0.117 & 0.126 & 0.115 & 0.119 & 0.002 & 37.52 & 62.47 & 97.38 & 2.61 \\
\hline & 312.5 & 0.113 & 0.126 & 0.119 & 0.119 & 0.003 & 37.52 & 62.47 & 97.38 & 2.61 \\
\hline & & 0.305 & 0.326 & 0.323 & 0.318 & 0.005 & 100 & 0 & & \\
\hline Control & & 0.126 & 0.118 & 0.135 & 0.126 & 0.004 & 39.72 & 60.27 & 100 & 0 \\
\hline vero & 1250 & 0.301 & 0.295 & 0.288 & 0.294 & 0.003 & 92.66 & 7.33 & 12.17 & 87.82 \\
\hline \multirow[t]{3}{*}{ HAV } & 625 & 0.158 & 0.183 & 0.174 & 0.171 & 0.006 & 53.98 & 46.01 & 76.34 & 23.65 \\
\hline & 312.5 & 0.138 & 0.124 & 0.125 & 0.129 & 0.003 & 40.56 & 59.43 & 98.60 & 1.39 \\
\hline & & 0.305 & 0.326 & 0.323 & 0.318 & 0.005 & 100 & 0 & & \\
\hline \multirow[t]{2}{*}{ Control } & & 0.169 & 0.142 & 0.155 & 0.155 & 0.006 & 48.84 & 51.15 & 100 & 0 \\
\hline & 1250 & 0.295 & 0.278 & 0.306 & 0.293 & 0.007 & 92.13 & 7.86 & 15.36 & 84.63 \\
\hline \multirow[t]{2}{*}{ CoxB } & 625 & 0.205 & 0.194 & 0.203 & 0.200 & 0.002 & 63.10 & 36.89 & 72.13 & 27.86 \\
\hline & 312.5 & 0.148 & 0.165 & 0.157 & 0.156 & 0.004 & 49.26 & 50.73 & 99.18 & 0.81 \\
\hline
\end{tabular}




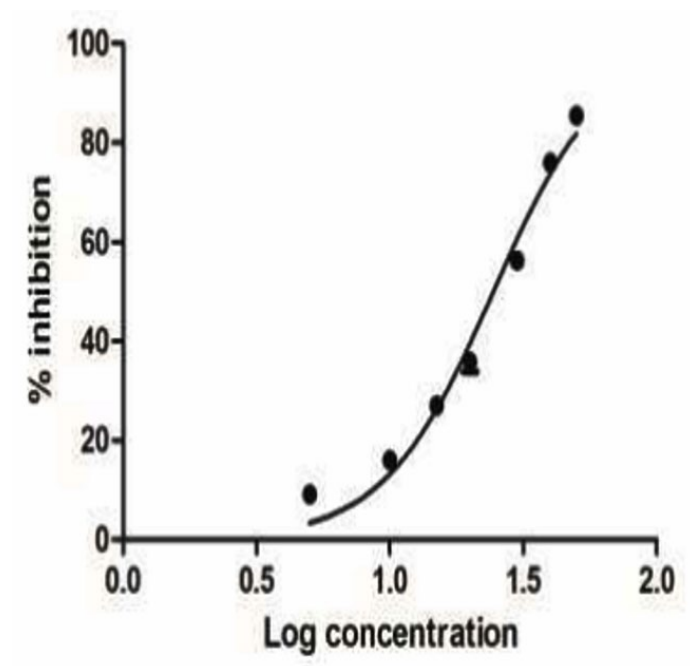

Fig. 9. Antioxidant activity of ethyl acetate crude extract. reducing potential, respectively. ${ }^{47}$ Antioxidant activity of Aspergillus species was also recognized in previous study. ${ }^{48}$ Marine fungi accompanying with Halopteris scoparia (Linnaeus) Sauvageau has been proven as antioxidant producers. ${ }^{21}$

Chemical characterization of ethyl acetate crude extract

Five peaks were distinguished in ethyl acetate crude extract of $A$. terreus SHE05 as shown in GC-MS chromatogram (Fig. 10). The peaks matching to the compounds that were recognized according to their height (\%), peak area (\%), peak retention time, and mass spectral fragmentation patterns to those of the identified compounds in Wiley spectral library collection. Spectral analysis (Fig. 11) revealed that the major components are Dodecanamine, N,N-Dimethyl with RT (11.95),

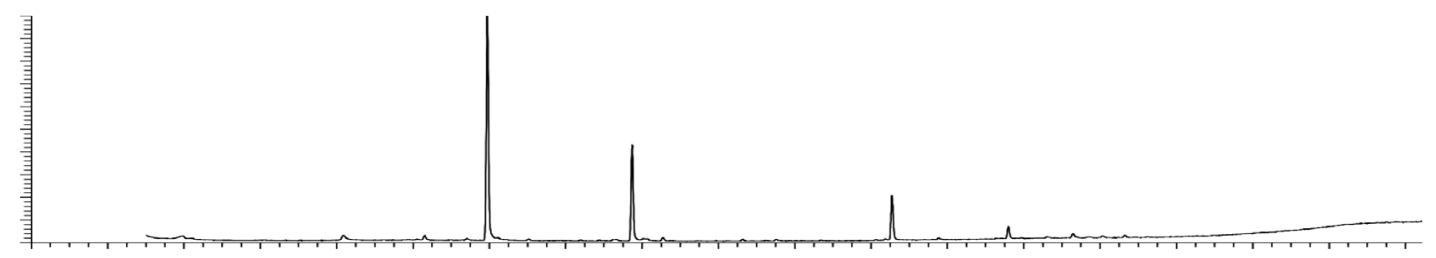

Fig. 10. Chromatogram showing ethyl acetate crude extract GC/MS

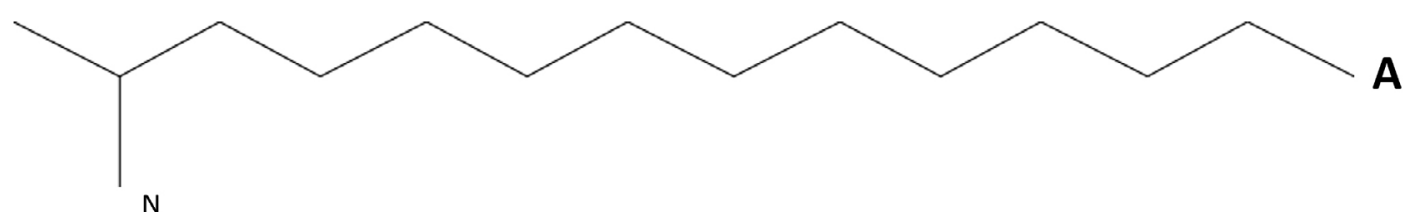

N

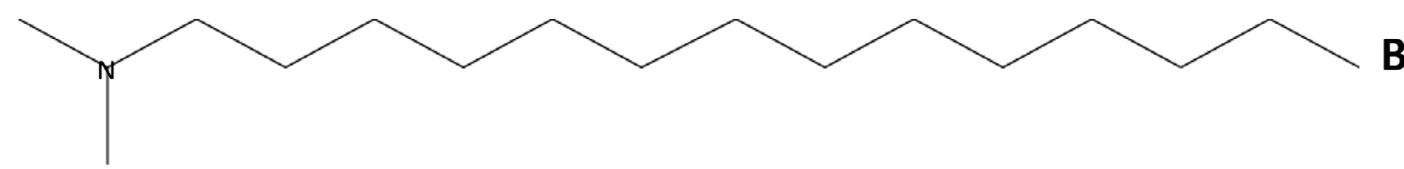

Fig. 11. Mass spectra of Tetradecanamine, $N, N$-Dimethyl (A) and Methylenebrexane (B).

molecular weight (213), area \% (55.46) and molecular formulaC ${ }_{14} \mathrm{H}_{31} \mathrm{~N}$; 1 - Tetradecanamine, $\mathrm{N}, \mathrm{N}$-Dimethyl with RT $(15,74)$, molecular weight (241), area \% (23.02) and molecular formula $\mathrm{C}_{16} \mathrm{H}_{35} \mathrm{~N}$ and Methylenebrexane with RT (22.55), peak area (11.22) and molecular formula $\mathrm{C}_{10} \mathrm{H}_{14}$.

Tetradecanamine, $\mathrm{N}, \mathrm{N}$-Dimethyl was reported as one of the major compounds produced by Citrullus colocynthis, furthermore, exhibited antimicrobial activity against $K$. pneumoniae, S. aureus, $P$. aeruginosa, Proteus mirabilis and $E$. coli with the highest inhibition zone against $P$. aeruginosa (4.91 \pm 0.260 to $1.03 \pm 0.200) .{ }^{45}$

\section{CONCLUSION}

Aspergillus terreus SHE05 isolated from Abu-Qir Bay, Egypt, has a notable antimicrobial, anticancer, antiviral and antioxidant activities, 
which encourage the use of its metabolites as natural products alternative to the traditional antimicrobial agents for industrial and medical applications.

\section{ACKNOWLEDGMENTS}

None.

\section{CONFLICT OF INTEREST}

The authors declare that there is no conflict of interest.

\section{AUTHORS' CONTRIBUTION}

All authors listed have made a substantial, direct and intellectual contribution to the work, and approved it for publication.

\section{FUNDING}

None.

\section{DATA AVAILABILITY}

The datasets generated and/or analysed during the current study are available from the corresponding author on reasonable request.

\section{ETHICS STATEMENT}

This article does not contain any studies with human participants or animals performed by any of the authors.

\section{REFERENCES}

1. Levy SB, Marshall B. Antibacterial resistance worldwide: causes, challenges and responses. Nat Med. 2004;10(Suppl.):S122-S129. doi: 10.1038/ $\mathrm{nm} 1145$

2. Ng TB, Cheung RCF, Wong JH, Bekhit AA, Bekhit AE. Antibacterial products of marine organisms. Appl Microbiol Biotechnol. 2015;99(10):4145-4173. doi: 10.1007/s00253-015-6553-x

3. Nazar S, Ravikumar S, Prakash Williams G, Syed Ali M, Suganthi P. Screening of Indian coastal plant extracts for larvicidal activity of Culex quinquefaciatus. Indian J Sci Technol. 2009;2(3):24-27. doi: 10.17485/ijst/2009/ v2i3/29407

4. Ravikumar S, Thajuddin N, Suganthi P, Jacob SI, Vinodkumar T. Bioactive potential of seagrass bacteria against human bacterial pathogens. J Environ Biol. 2010;31(3):387-389. https://www.researchgate.net/ publication/47674939

5. Trinh VPT, Ngoc NTD, Trang VTD, et al. Antimicrobial activity of marine Fungi isolated from the Son Tra peninsula, Da Nang, Vietnam. Academia Journal of Biology. 2017;39(4):457-462. doi: 10.15625/0866$7160 / v 39 n 4.8889$
6. Kuo J, Chan C, Chi W. Isolation of endophytic fungi with antimicrobial activity from medicinal plant Zanthoxylum simulans Hance. Folia Microbiologica. 2021;66(3):385-397. doi: 10.1007/s12223-021-008544

7. Singh RP, Kumari P, Reddy CR. Antimicrobial compounds from seaweeds associated bacteria and fungi. Appl Microbiol Biotechnol. 2015;99(4):1571-1586. doi: 10.1007/s00253-014-6334-y

8. Al-Fakih AA, Almaqtri WQA. Overview on antibacterial metabolites from terrestrial Aspergillus spp. Mycology 2019;10(4):191-209. doi: 10.1080/21501203.2019.1604576

9. Ibrahim SRM, Elkhayat ES, Mohamed GA, et al. Aspernolides $F$ and $G$. new butyrolactones from the endophytic fungus Aspergillus terreus. Phytochem. Lett. 2015b; 14: 84-90. doi: 10.1016/j. phytol.2015.09.006

10. Cazar ME, Schmeda-Hirschmann G, Astudillo L. Antimicrobial butyrolactone I derivatives from the Ecuadorian soil fungus Aspergillus terreus Thorn. var terreus. World J microb biot. 2005;21(6-7):1067-1075. doi: 10.1007/s11274-004-8150-5

11. Tian $Y Q$, Lin XP, Wang $Z$, et al. Asteltoxins with antiviral activities from the marine sponge-derived fungus Aspergillus sp. SCSIOXWS02F40. Molecules. 2016;21(1):E34. doi: 10.3390/molecules21010034

12. Ma X, Nong $X$, Ren $Z$, et al. Antiviral peptides from marine gorgonian-derived fungus Aspergillus sp. SCSIO 41501. Tetrahedron Lett. 2017a;58(12):1151-1155. doi: 10.1016/j.tetlet.2017.02.005

13. AL-maqtoofi MY, Burghal AA, AL-Muosawi AA. Screening of Antibacterial Activity from Aspergillus species Treated with Synthetic Antifungal Agent. Asian J Microbiol Biotechnol Environ Sci. 2019;21(2):335-338. https://www.researchgate.net/ publication/335096902

14. Rajeswari P, Jose PA, Amiya R, Jebakumar SR. Characterization of saltern based Streptomyces $\mathrm{sp}$. and statistical media optimization for its improved antibacterial activity. Front Microbiol. 2015;5:753. doi: 10.3389/fmicb.2014.00753

15. Navarrete-Bolanos JL, Tellez-Martinez GP, MirandaLopez R, Jimenez-Islas H. An Experimental Strategy Validated to Design Cost-Effective Culture Media Based on Response Surface Methodology.Prep Biochem Biotechnol. 2017;47(6):578-588. doi: 10.1080/10826068.2017.1280825

16. Feng J, Zhang W, Han L, Zhang X. Statistical optimization of medium components to improve antibiotic activity of Streptomyces sp. 19G- 317. Afr J Agric. Res. 2011;6:4424-4431. doi: 10.5897/AJAR10.945

17. Kavitha MD, Kathiresan S, Bhattacharya S, Sarada R. Culture media optimization of Porphyridium purpureum: production potential of biomass, total lipids, arachidonic and eicosapentaenoic acid. J Food Sci Technol. 2016;53(5):2270-2278. doi: 10.1007/ s13197-016-2185-0

18- Xu L, Wei K, Jiang J, Zhang L. Extraction Optimization of Astragaloside IV by response surface methodology and evaluation of its stability during sterilization and storage. Molecules. 2021;26:2400. doi: 10.3390/ 


\section{molecules 26082400}

19. Xu Z, Cai Y, Ma Q, Zhao Z, Yang D, Xu X. Optimization of Extraction of Bioactive Compounds from Baphicacanthus cusia leaves by hydrophobic Deep eutectic solvents. Molecules. 2021;26(6):1729. doi: 10.3390/molecules26061729

20. Bestawy E, El-Shenway M, Abou-Elela G, Gohar YM, Wefky SM. Identification and distribution of antimicrobial- active marine bacteria along the heavily polluted coastal area of Alexandria, Egypt. Water Sci Technol. 2011;63(6):1081-1092. doi: 10.2166/ wst.2011.345

21. Calado MdL, Silva J, Alves C, et al. Marine endophytic fungi associated with Halopteris scoparia (Linnaeus) Sauvageau as producers of bioactive secondary metabolites with potential dermocosmetic application. PLOSONE. 2021;16(5):e0250954. doi: 10.1371/journal. pone. 0250954

22. Samuel P, Prince L, Prabakaran P. Antibacterial activity of marine derived fungi collected from South East coast of Tamilnadu, India. J Microbiol Biotechnol. 2011;1(4):86-94. http://scholarsresearchlibrary.com/ archive.html

23. Hassan SWM. Antibacterial, anticoagulant and antiinflammatory activities of marine Bacillus cereus S1. J Pure Appl Microbiol. 2016;10(4):2593-2606. doi: 10.22207/JPAM.10.4.15

24. White TJ, Bruns T, Lee S, Taylor J. Amplification and direct sequencing of fungal ribosomal RNA genes for phylogenetics. In PCR Protocols: A guide to Methods and Applications (ed. MA Innis, DH Gelfand JJ. Sninsky \& TJ White). 1990:315-322. Academic Press: San Diego, U.S.A. doi: 10.1016/B978-0-12-372180-8.50042-1

25. Plackett RL, Burman JP. The design of optimum multifactorial experiments. Biometrika. 1946;33:305325. doi: 10.1093/biomet/33.4.305

26. Yu X, Hallett SG, Sheppard J, Watson AK. Application of Plackett-Burman experimental design to evaluate nutritional requirements for the production of Colletorichum coccodes spores. Appl Microbiol Biotechnol. 1997;47:301-305. doi: 10.1007/ s002530050930

27. Box GE, Behnken DW. Some new three level designs for the study of quantitative variables. Technometrics. 1960;2(4):455-475. doi: 10.1080/00401706.1960.10489912

28. Ashengroph M, Saedi D. Optimization of Selenite Removal by Lactobacillus sp. Tra cheese 6 using Box-Behnken design. J Kerman University Med Sci. 2016;23(4):466-482. http://vlib.kmu.ac.ir/kmu/ handle/kmu/214947

29. Hassan SWM, Abd El-latif HH. Characterization and applications of the biosynthesized silver nanoparticles by marine Pseudomonas sp. H64.J Pure Appl Microbiol. 2018;12(3):1289-1299. doi: 10.22207/JPAM.12.3.31

30. Lotfy WA, Mostafa SW, Amr AA, Ghanem KM. Production of di-(2-ethylhexyl) phthalate by Bacillus subtilis AD35: Isolation, purification, characterization and biological activities. Microb Pathog. 2018;124:89100.doi: 10.1016/j.micpath.2018.08.014

31. Hawkey PM. The origins and molecular basis of antibiotic resistance. Br Med J. 1998;317(7159): 657-
660. doi: $10.1136 / \mathrm{bmj} .317 .7159 .657$

32. Kalyani BS Krishna P, Sreenivasulu K. Screening and identification of novel isolate Streptomyces sp., NLKPB45 from Nellore costal region for its biomedical applications. Saudi J Biol Sci. 2019;26(7):1655-1660. doi: 10.1016/j.sjbs.2018.08.027

33. Ababutain M, Aldosary SK, Aljuraifani AA, et al. Identification and Antibacterial Characterization of Endophytic Fungi from Artemisia sieberi Ibtisam. Int J Microbiol. 2021;2021:6651020. doi: 10.1155/2021/6651020

34. Alberts JF, Gelderblom WCA, Thiel PG, Marasas WFO, Vanschalkwyk DJ, Behrend Y. Effects of temperature and incubation period on production of Fumonisin B1 by Fusarium moniliforme. Appl Environ Microbiol. 1990;56(6):1729-1733. doi: 10.1128/aem.56.6.17291733.1990

35. Kaur H, Arora DS. Effect of various physiological parameters on antimicrobial activity of Aspergillus terreus. World J Pharm Res. 2015;4(9):1531-1544. www.wjpr.net

36. Lamrani K, Lakhtar $\mathrm{H}$, Alaoui MI, et al. Production of fumagillin by Aspergillus fumigatus isolated from traditional trituration units, "Maasra", in Morocco. Micol Aplicada Int. 2008;20(1):35-41. http://www. redalyc.org/articulo.oa?id $=68520104$

37. Abdou DAM, El-Far NA, Shetaia YM, Abou-Elmagd WSI, El-Din AAK. Exploring the antimicrobial potential of local marine fungi. Egypt J Exp Biol (Bot.). 2016;12(2):275288. doi:10.5455/eg yjebb.20161221102915

38. Bhattacharyya, P.N., and Jha, D.K. Optimization of culture conditions affecting growth and improved bioactive metabolite production by a subsurface Aspergillus strain TSF 146. Int. J. Appl. Biol. Pharmaceut. Technol. (2011); 2(4): 134-143.

39. Guo L, Wang C. Optimized production and isolation of antibacterial agent from marine Aspergillus flavipes against Vibrio harveyi. 3 Biotech. 2017;7:383. doi: 10.1007/s13205-017-1015-z

40. Handayani D, Artasasta MA, Mutia D, Atikah N, Rustini, Tallei TE. Antimicrobial and cytotoxic activities screening of fungal secondary metabolites isolated from marine sponge Callyspongia sp. AACL Bioflux. 2021;14(1):249-258. http://www.bioflux.com.ro/aacl

41. Narayana KJP, Ravikiran D, Vijayalakshmi M. Screening of Streptomyces species from cultivated soil for broadspectrum antimicrobial compounds. Asian J Microbiol Biotechnol Environ Sci. 2005;7:121-124.45.

42. Remya $\mathrm{M}, \mathrm{Vijayakumar} \mathrm{R}$. Isolation and characterization of marine antagonistic actinomycetes from West Coast of India. FU Med Biol. 2008;15:13-19. https://www. researchgate.net/publication/228654972.

43. Thorati M, Mishra JK. Antibacterial activity of crude extract from Aspergillus niger isolated from the stilt roots of Rhizophora apiculata along South Andaman coast, India. J Pharmacogn Phytochem. 2017;6(5):1635-1638.

44. Mansoori B, Mohammadi A, Davudian S, Shirjang S, Baradaran $B$. The different mechanisms of cancer drug resistance: a brief review. Adv Pharm Bull. 2017;7(3):339-348. doi: 10.15171/apb.2017.041

45. El-Sayed ASA, Shindia AA, Ali GS, et al. Production 
and bioprocess optimization of antitumor Epothilone $B$ analogue from Aspergillus fumigatus, endophyte of Catharanthus roseus, with response surface methodology. Enzyme Microb Technol. 2021;143:109718. doi: 10.1016/j. enzmictec.2020.109718

46. Yadav M, Yadav A, Yadav JP. In vitro antioxidant activity and total phenolic content of endophytic fungi isolated from Eugenia jambolana Lam. Asian Pac J. 2014;7(1):S256-S261. doi: 10.1016/S19957645(14)60242-X
47. Saleh A, MEl-Refaie HA, Hashem AM, El-Menoufy HA, Mansour NM, El-Beih AA. Optimization studies and chemical investigations of Aspergillus terreus-18 Showing Antioxidant Activity. Egypt J Chem. 2019;62(2):215-230. doi: 10.21608/ EJCHEM.2018.4921.1438

48. Idan SA, Al-Marzoqi AH, Hameed IH. Spectral analysis and anti-bacterial activity of methanolic fruit extract of Citrullus colocynthis using gas chromatography-mass spectrometry. Afr J Biotechnol. 2015;14(46):31313158. doi: 10.5897/AJB2015.14957 